\title{
Selected parameters of maize straw briquettes combustion
}

\author{
Artur Kraszkiewicz ${ }^{1, *}$, and Ignacy Niedziółka ${ }^{2}$ \\ ${ }^{1}$ University of Life Sciences in Lublin, Section of Management of Agriculture Machines and Eco-Energetic Systems, Głęboka 28, \\ 20-612 Lublin, Poland \\ ${ }^{2}$ University of Life Sciences in Lublin, Department of Agricultural, Forest and Transport Machinery, Głęboka 28, 20-612 Lublin, \\ Poland
}

\begin{abstract}
An analysis of the process of burning briquettes made of maize straw was performed. A number of traits have been evaluated, including physical characteristics of the fuel through parameters describing combustion kinetics as well as products and combustion efficiency. The study was conducted in a grate boiler, during which the differentiating factor was the air velocity flowing to the boiler. It was observed that the obtained values of the considered parameters were different, particularly temperature of the flue gas and the amount of $\mathrm{CO}$ and $\mathrm{SO}_{2}$ in the flue gas.
\end{abstract}

\section{Introduction}

Biomass fuels are gaining popularity due to their renewable nature and potential reduction of pollution generation. The biomass usually contains minor amounts of sulfur, heavy metals and is considered neutral for greenhouse gas emissions. The problem with its energetic use is its variability in the physical and chemical characteristics of the plant species and the forms of biofuels produced. At the same time, the conversion of biomass into heat energy, which is available in a wide range of heating devices, makes each of them requires separate operational settings dedicated to the fuel used so as to achieve high combustion efficiency with the highest possible heat transfer and the lowest emission of pollutants into the atmosphere, both gaseous and solid. Gases such as $\mathrm{CO}, \mathrm{NO}, \mathrm{SO}_{2}$, that appear in the atmosphere due to badly run combustion process, adversely affect the human health. Incomplete combustion of carbonaceous material can lead to carbon monoxide (CO) emissions. Carbon monoxide is a colorless and odorless gas, and it is poisonous for living beings, because it binds to hemoglobin during contact with blood, to which it has 200-240 times higher affinity than oxygen. Concentration of $125 \mathrm{mg} \cdot \mathrm{m}^{-3} \mathrm{CO}$ in the air and the impact on humans in 1 hour (according to the World Health Organization, WHO) causes the binding of $4 \%$ blood hemoglobin and triggers cardiac disorders. The value of $250 \mathrm{mg} \cdot \mathrm{m}^{-3}$ carbon monoxide (II) in the air can cause death $[1,2]$. Another characteristic element in solid biomass is nitrogen $(\mathrm{N})$. During fuel combustion, nitrogen is almost completely converted to gaseous $\mathrm{N}_{2}$ and nitrogen oxides (NOx). The most dangerous is $\mathrm{NO}_{2}$, which is characterized by acute odor with acid taste and reddish brown color. Passing a person in a $\mathrm{NO}_{2}$ environment at the concentration of $0.5-1.5 \mathrm{ppm}$ within 1 hour will cause breathing difficulties. On the other hand,
NO is a poorly reactive, odorless and colorless gas, which, unfortunately, in the Earth's atmosphere, under the influence of UV rays, is converted into $\mathrm{NO}_{2}$. A similar reactivity is revealed by nitrous oxide, called the laughing gas, generated during low-temperature fuel combustion. It is counted among the most active gases that prevent sudden heat radiation of the Earth surface into space, thus contributing to the creation of the greenhouse effect $[1,2]$. Sulfur (S) contained in the fuel during combustion is bound in ash or enters the atmosphere with exhaust gases mainly in the form of sulfur dioxide $\left(\mathrm{SO}_{2}\right)$ and less often as sulfur trioxide $\left(\mathrm{SO}_{3}\right) \cdot \mathrm{SO}_{2}$ is a colorless gas with a sharp and pungent smell, strongly irritating the respiratory tract. Sulfur dioxide is poisonous to animals and harmful to plants and contributes to atmospheric pollution when generated during the fuels combustion (smog). Rybak [3] reported that monitoring of combustion temperature in the furnace plays a fundamental role in modifying the combustion mechanism, controlling the emission of harmful substances, and optimizing the efficiency and operation of the whole system. The furnace temperature can be controlled by manipulating a number of parameters, with the most important and not relevant to the combustion chamber and related to the physical and chemical characteristics of the fuel being the value of the air ratio excess, the oxidation temperature, and the moisture content.

Among the wide range of biomass fuels, maize straw is an interesting raw material. Maize is one of the main cereal crops grown in Poland, and its straw is considered an interesting source of a biomass for energy purposes $[4,5]$. The analysis of the combustion process and explanation of the mechanism of maize straw combustion on a fixed bed will contribute to the clean and efficient use of maize straw as a source of energy.

\footnotetext{
${ }^{*}$ Corresponding author: artur.kraszkiewicz@,up.lublin.pl
} 
The purpose of the study was to analyze the process of maize straw briquettes combustion in terms of the dependence of the influence of air velocity on the achieved combustion temperatures as well as on the emission of carbon monoxide, nitrogen and sulfur.

\section{Material and methods}

\subsection{Biomass types and sample preparation}

- Maize straw briquettes were used for the study. The selected physical and chemical parameters of this fuel were determined applying the following research methods:

- external dimensions of the fuel - by direct measurement of 10 randomly selected briquettes;

- moisture content - weight method according to the standard PN-EN 14774-1:2010 [6];

- density - indirect method using the mass and volume of 10 randomly selected briquettes and calculated according to Annex A of the standard PN-EN 15150:2012 [7];

- carbon, hydrogen, sulfur - by IR absorption method;

- nitrogen - katharometric method;

- calorific value - calculated after prior determination of combustion heat according to the standard PNEN 14918:2010 [8];

- ash content - according to the standard PN-EN 14775:2010 [9].

Mean values of the obtained results are shown in Table 1.

Table 1. Physical and chemical properties of maize straw briquettes.

\begin{tabular}{|c|c|c|c|}
\hline \multicolumn{2}{|c|}{ Parameter } & Unit & $\begin{array}{c}\text { Maize straw } \\
\text { briquettes } \\
\text { (average values) }\end{array}$ \\
\hline \multicolumn{2}{|l|}{ Length } & $\mathrm{mm}$ & 23 \\
\hline \multicolumn{2}{|c|}{ Diameter } & $\mathrm{mm}$ & 50 \\
\hline \multicolumn{2}{|c|}{ Total moisture } & $\%$ & 7.92 \\
\hline \multicolumn{2}{|c|}{ Density } & $\mathrm{kg} \cdot \mathrm{m}^{-3}$ & 900 \\
\hline \multirow{4}{*}{ 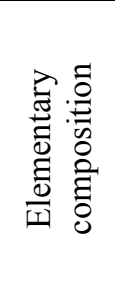 } & $\mathrm{C}$ & $\%$ & 45.0 \\
\hline & $\mathrm{H}$ & $\%$ & 5.50 \\
\hline & $\mathrm{N}$ & $\%$ & 0.70 \\
\hline & $\mathrm{S}$ & $\%$ & 0.18 \\
\hline \multicolumn{2}{|c|}{ Calorific value } & $\mathrm{MJ} \cdot \mathrm{kg}^{-1}$ & 16.43 \\
\hline \multicolumn{2}{|c|}{ Net calorific value } & $\mathrm{MJ} \cdot \mathrm{kg}^{-1}$ & 15.10 \\
\hline \multicolumn{2}{|c|}{ Ash content } & $\%$ & 5.77 \\
\hline
\end{tabular}

\subsection{Combustion process conditions}

During the study, a test bench with a water-jacketed, rectangular combustion chamber closed from the bottom with the water grid (Figure 1), was used. The capacity of the combustion chamber to the exchanger part was 3.51 $\mathrm{dm}^{3}(0.26 \times 0.3 \times 0.45 \mathrm{~m})$. Above the combustion chamber, there was a heat exchanger with horizontal divisions with water channels. The ash chamber was below the water grid, in which the ash container was placed. The whole device was extended by an air supply fan directed beneath the grate and the circulation fluid pump placed between the boiler and the storage tank working in the open system. The water jacket capacity was $30 \mathrm{dm}^{-3}$, and that of accumulation tank $400 \mathrm{dm}^{-3}$. This system was supposed to provide a similarity to the actual chambers and allow the combustion process to be carried out as in low-power heating devices.

The exhaust gases were collected from the chimney at a distance of $1 \mathrm{~m}$ from the flue boiler. The measuring probe was connected to the PGD-100 exhaust gas drier (Madur Eljack Electronics), from which exhaust gases were sent to the exhaust gas analyzer. During the tests, Photon's portable flue gas analyzer was used. This is a device based on infrared sensors (NDIR) for the following gases: $\mathrm{CO}, \mathrm{CO}_{2}, \mathrm{NO}, \mathrm{SO}_{2}$. The temperature was measured using a $\mathrm{K}$ type thermocouple. The first one was located in the middle of the height of the combustion chamber at its outer wall, while the second one performed measurements of the flue gas temperature in the chimney and was located at the exhaust gas collection point (Figure 1).

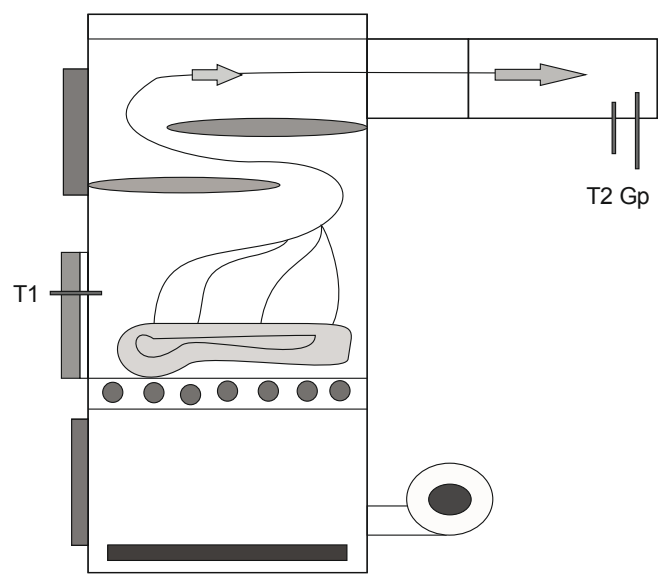

Fig. 1. Scheme of the test bench (combustion chamber): T1 temperature measurement in the combustion chamber, T2 temperature measurement in the chimney, Gp - exhaust gas consumption.

The study consisted of combusting the 1 kilogram samples of maize straw briquettes in triplicates at four velocities of the supplied air stream $-0.5 \mathrm{~m} \cdot \mathrm{s}^{-1}$ (A), 1.0 $\mathrm{m} \cdot \mathrm{s}^{-1}$ (B), $1.5 \mathrm{~m} \cdot \mathrm{s}^{-1}$ (C), $2.5 \mathrm{~m} \cdot \mathrm{s}^{-1}$ (D). Fuel loading and ash removal were handled manually. Measurements of the exhaust gas composition were carried out continuously from the time the fuel was laid on the stabilized layer of heat until the reaction complete. The results of these parameters were recorded automatically to the analyzer database every 2 seconds with simultaneous recording of data recording duration. The database created was transferred from the analyzer to a PC after the tests. The results of the study were statistically analyzed in Statistica 10.0 software. The 
Shapiro-Wilk test verified compatibility of the results with the normal distribution, and the Brown-Forsyth test estimated variance homogeneity. When homogeneity of variance was absent, the Kruskal-Wallis test was used. In contrast, the Spearman correlation test was used to describe relationships between individual variables. Moreover, the observed differences were found to be statistically significant at the significance level $\mathrm{p}<0.05$.

\section{Results}

Average values of temperatures in the combustion chamber and in the chimney are shown in Figures 2 and 3 , respectively.

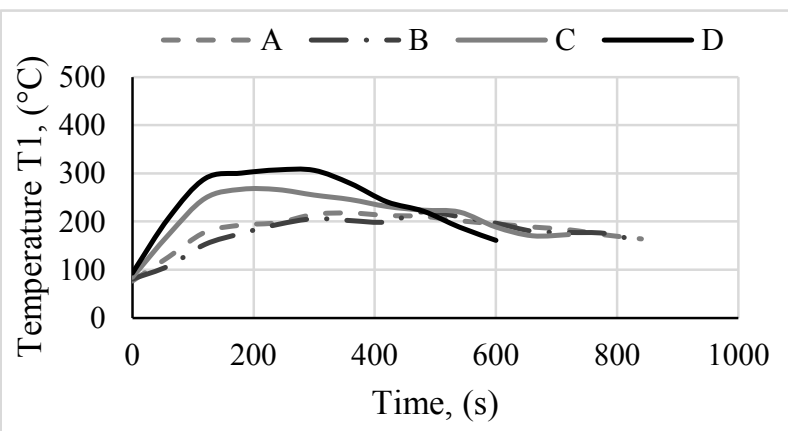

Fig. 2. Temperature changes in the combustion chamber during combustion of maize straw briquettes.

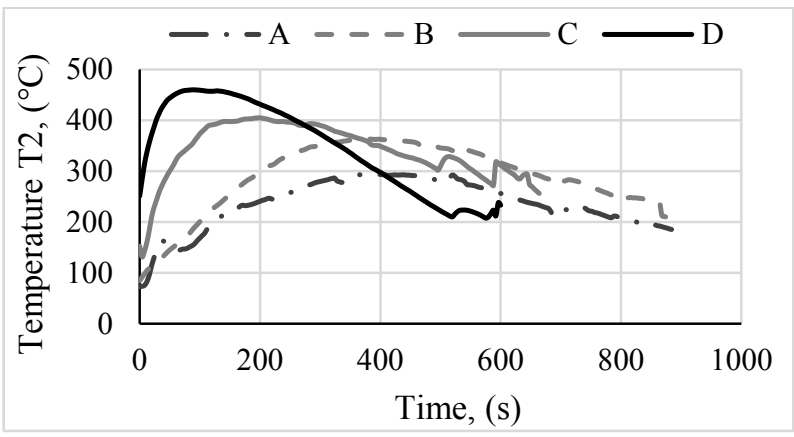

Fig. 3. Temperature changes in the chimney during combustion of maize straw briquettes.

As the air velocity increases from $0.5 \mathrm{~m} \cdot \mathrm{s}^{-1}$ to 2.5 $\mathrm{m} \cdot \mathrm{s}^{-1}$, the combustion temperature increases both in the flue channel and in the combustion chamber. At the same time, the burning time of the fuel sample is reduced from less than 15 minutes to 10 minutes, and for the fastest speed of this medium, much shorter time is required to reach the maximum temperature. Temperature T2 (in the flue channel) was about 100-150 ${ }^{\circ} \mathrm{C}$ higher than the temperature $\mathrm{T} 1$ (in the combustion chamber) - Figures 2 and 3.

Composition of the combustion gases generated during the combustion of maize straw briquettes under combustion conditions assumed in the tests is shown in Figures 4-6.

Only for the highest velocity of the air supplied to the boiler, the amount of NO particles in the exhaust gas reached the maximum value in the first minute of combustion. At this time, at the highest air velocity, a temporary increase in temperature $\mathrm{T} 2$ was also observed
- Figures 3. There was a difference in $\mathrm{SO}_{2}$ content in the exhaust gas. At the smallest airflow velocities in the first period, the $\mathrm{SO}_{2}$ content of the exhaust gas amounted up to $120 \mathrm{ppm}$. After the first 3 minutes of combustion, these values were reduced and stabilized to a range of 40 to $60 \mathrm{ppm}$.

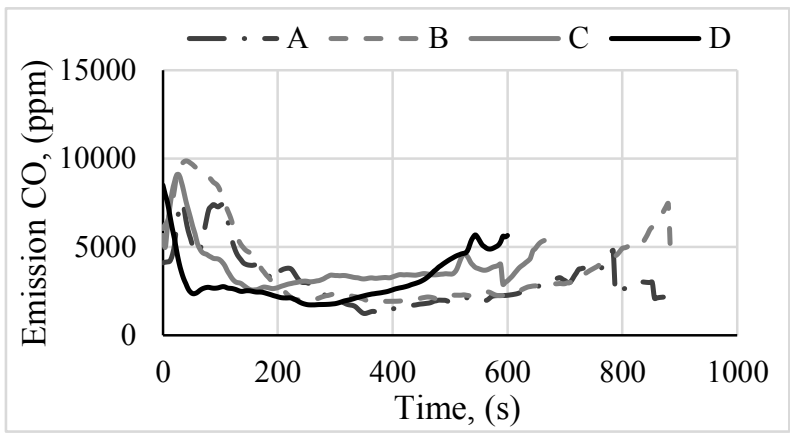

Fig. 4. Changes of the concentration of carbon monoxide during combustion of maize straw briquettes.

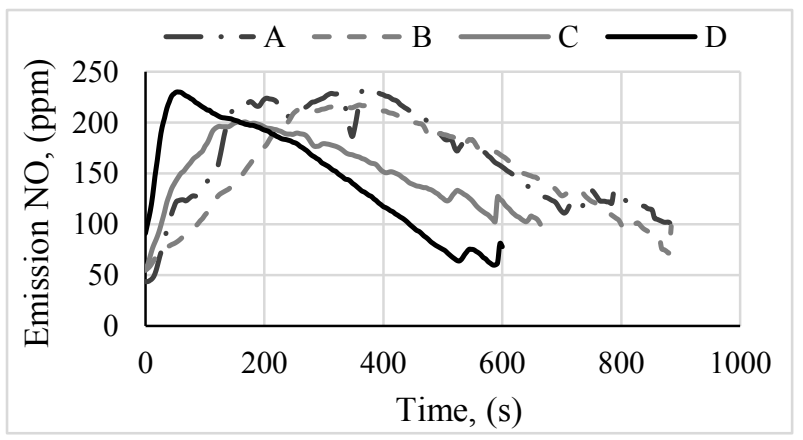

Fig. 5. Changes of the concentration of nitrogen oxide during combustion of maize straw briquettes.

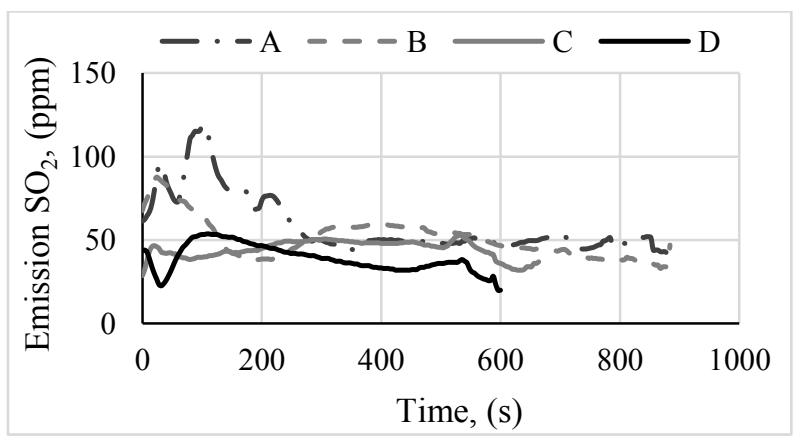

Fig. 6. Changes of the concentration of Sulphur dioxide during combustion of maize straw briquettes.

The statistical analysis of the obtained results indicated the use of the non-parametric Kruskall-Wallis test. Results of this test indicated significant differences between values obtained for the following components of exhaust gas: $\mathrm{CO}, \mathrm{SO}_{2}$ as well as between the temperature in the chimney. No significant differences were found between the number of NO particles in the flue gases that were recorded during tests at varying velocity of supply air to the boiler. Probability was 0.7193. The results of the $\mathrm{T} 2$ temperature correlation tests performed with the combustion products are shown in Table 2. 
Table 2. Spearman's correlation coefficients between temperature and gaseous combustion products.

\begin{tabular}{|l|c|c|c|c|c|c|c|c|}
\hline \multirow{2}{*}{ Variables } & \multicolumn{7}{|c|}{ Air velocity $\left(\mathbf{m} \cdot \mathbf{s}^{-1}\right)$} \\
\cline { 2 - 9 } & $\mathbf{0 . 5}(\mathbf{A})$ & \multicolumn{2}{c|}{$\mathbf{1 . 0}(\mathbf{B})$} & \multicolumn{1}{|c|}{$\mathbf{1 . 5}(\mathbf{C})$} & \multicolumn{2}{|c|}{$\mathbf{2 . 5}(\mathbf{D})$} \\
\cline { 2 - 9 } & $\mathbf{R}$ & $\mathbf{p}$ & $\mathbf{R}$ & $\mathbf{p}$ & $\mathbf{R}$ & $\mathbf{p}$ & $\mathbf{R}$ & $\mathbf{p}$ \\
\hline $\begin{array}{l}\mathrm{T} 2\left({ }^{\circ} \mathrm{C}\right) \\
\text { vs CO } \\
(\mathrm{ppm})\end{array}$ & -0.74 & 0.00 & -0.77 & 0.00 & -0.30 & 0.00 & -0.40 & 0.00 \\
\hline $\begin{array}{l}\mathrm{T} 2\left({ }^{\circ} \mathrm{C}\right) \\
\text { vs NO } \\
(\mathrm{ppm})\end{array}$ & 0.75 & 0.00 & 0.92 & 0.00 & 0.93 & 0.00 & 0.94 & 0.00 \\
\hline $\begin{array}{l}\mathrm{T} 2\left({ }^{\circ} \mathrm{C}\right) \\
\text { vs SO})_{2} \\
(\mathrm{ppm})\end{array}$ & -0.46 & 0.00 & 0.19 & 0.00 & 0.44 & 0.00 & 0.62 & 0.00 \\
\hline
\end{tabular}

\section{Discussion}

Maize straw, or rather briquettes, made from this raw material used for testing, have typical properties corresponding to such form and type of biomass [10-14]. Burning the plant biomass such as wood and wheat or rye straw compacted into briquettes and pellets in heating devices has been well researched [15-19]. However, maize straw causes burning problems as recorded in the work by Zhao et al. [20].

Fuel characteristics and process conditions such as fuel type, particle size, airflow and fuel humidity affect the combustion characteristics by changing the heat generation, heat transfer rate, and reaction speed. The properly performed combustion process is dependent on the amount of oxygen supplied and actually on the amount of air [21-23]. Airflow is a key parameter in the process that determines the amount of available oxygen and convection heat transfer. Process indicators are classified in three successive groups depending on the air velocity: oxygen limitation, reaction limitation and extinguishing by convection systems [20, 24, 25].

However, variability of the recorded data (temperature, gaseous combustion products) identifies two distinct stages as the bed combustion progresses: (1) evaporation of the volatiles with transfer of the afterburning zone to the exchanger and flue gas zone as well as (2) oxidation of the coal residue.

Results obtained under the test conditions indicate that the NO concentration in the exhaust gas initially reaches a maximum and then decreases to a stable value after the bed is lit. Similar results were obtained by [22, 26]. The statistical analysis indicated that the NO content of the flue gas is insensitive to the change in velocity of air flowing into the combustion chamber. Other chemicals, $\mathrm{CO}$ and $\mathrm{SO}_{2}$, have such a relationship. On the other hand, the relationship between the temperature values recorded in the chimney and the combustion products showed a strong, positive dependence on the $\mathrm{NO}$ content of the flue gases and poor $\mathrm{CO}$ and $\mathrm{SO}_{2}$ dependence, especially when changing the velocity of supplied air. For CO, the force of temperature dependence decreased as the air velocity increased, and for $\mathrm{SO}_{2}$ this was the inverse relation.
As a result of the research, the following observations and conclusions were drawn up:

1. Maize straw briquettes, with respect to air velocity as the primary factor of differentiating the combustion process, generally show different parameters of this process. Only the NO content is not dependent on air velocity.

2. Effective ecological combustion of maize straw briquettes requires the use of heating devices with the possibility of adjusting the air supply depending on the demand of combusted fuels. However, using higher air velocities, the combustion zone must be shifted towards the chimney and the temperature of the flue gas will probably increase, especially in the initial combustion phase.

3. Due to the remarkable variation in physicochemical characteristics of solid biofuels and variety of technical parameters of heating equipment, it would be appropriate to extend the research to other species, and above all, forms of plant biomass and their impact on the combustion process in order to achieve tangible ecological and energy effects.

\section{References}

1. M. Domański, L. Dzurenda, M. Jabłoński, M. Osipiuk, Drewno jako materiat energetyczny (SGGW, Warszawa, 2007) in Polish

2. Y.S.H. Najjar, Ashdin Publishing Innovative Energy Policies, Vol. 1 (2011)

3. W. Rybak, Spalanie $i$ wspótspalanie biopaliw statych (Wyd. Politechniki Wrocławskiej Wrocław 2006) in Polish

4. H. Karcz, M. Kantorek, M. Grabowicz, K. Wierzbicki, Piece przemysłowe i kotły, XI-XII (2013) in Polish

5. I. Niedziółka, A. Zuchniarz, Motrol, Nr 8A (2006) in Polish

6. PN-EN 14774-1:2010 Solid biofuels Determination of moisture content - Oven dry method - Part 1: Total moisture - Reference method

7. PN-EN 15150:2012 Solid biofuels. Determination of particle density

8. PN-EN 14918:2010 Solid biofuels - Determination of net calorific value

9. PN-EN 14775:2010 Solid biofuels - Determination of ash content

10. A. Demirbas, Prog. Energy Combust Sci., Vol. 30, Issue 2 (2004)

11. M.H. Eisenbies, T.A. Volk, A. Biomass and Bioenergy, 86 (2016)

12. P. Mc Kendry, Bioresource Technology, 83 (2002)

13. I. Obernberger, T. Brunner, G. Bärnthaler, Biomass Bioenergy, 30 (2006)

14. M. Stolarski, M. Krzyżaniak, M. Śnieg, E. Słomińska, M. Piórkowski, R. Filipkowski, Int. Agrophys., 28 (2014)

\section{Conclusions}


15. J.J. Saastamoinen, R. Taipale, M. Horttanainen, P. Sarkomaa, Combust Flame. Volume 123, Issues 1-2, (2000)

16. R.P. Van der Lans, L.T. Pedersen, A. Jensen, P. Glarborg, K. Dam-Johansen, Biomass and Bioenergy, Volume 19, Issue 3 (2000)

17. Y.B. Yang, J. Swithenbank, V.N. Sharifi, Fuel, Volume 83, Issues 11-12 (2004)

18. H.C. Smit, M. Meincken. Biomass and Bioenergy 39 (2012)

19. L. Carvalhoa, E. Wopienkaa, Ch. Pointnera, J. Lundgrenb, V. K. Vermaa, W. Haslingera, Ch. Schmidla, Applied Energy, Volume 104 (2013)

20. W. Zhao, Z. Li, D. Wang, Q. Zhu, R. Sun, B. Meng, G. Zhao, Bioresour. Technol.,99(8) (2007)

21. T. Nussbaumer, Swiss Federal Office for the Environment (FOEN) as a contribution to the expert Group on Techno-Economic Issues (EGTEI) under the Convention on Long-Range Transboundary Air Pollution, Verenum Press Zürich (Switzerland), (2010)

22. A. Gungor, Biomass and Bioenergy 34 (2010)

23. Ch. Ryu, Y.B. Yang, A. Khor, N.E. Yates, V.N. Sharifi, J. Swithenbank, Fuel, 85 (2006)

24. D. Shin, S. Choi, Combust Flame, Volume 121, Issues 1-2 (2000)

25. H. Zhou, A.D. Jensen, P. Glarborg, P.A. Jensen, A. Kavaliauskas, Fuel, 84 (2005)

26. H. Zhou, A.D. Jensen, P. Glarborg, A. Kavaliauskas, Fuel, 85 (2006) 